\title{
Validated ejector model for hybrid system applications
}

\author{
M.L. Ferrari, M. Pascenti, A.F. Massardo \\ Thermochemical Power Group (TPG) \\ University of Genoa, Italy \\ Contact author: Mario L. Ferrari (mario.ferrari@unige.it)
}

\begin{abstract}
The aim of this work is the presentation of a new model for ejector performance calculation using a commercial tool. Due to the critical issues in recirculation performance, special attention is devoted to applications in hybrid systems based on high temperature fuel cells. The theoretical activity is supported by an experimental rig able to operate tests on ejectors at different operative conditions, with a layout similar to the fuel cell anodic recirculation. The model validation, operated considering experimental data obtained with this rig, is essential to evaluate the tool performance for design and off-design calculations. This aspect is particularly critical due to important limitations in the recirculation ratio (especially for the anodic side), to avoid unacceptable operative conditions in the fuel cells.

The results presented in this work were obtained with this validated model for an ejector applied on the anodic side of a Solid Oxide Fuel Cell (SOFC). A parametric analysis was carried out to show the effects of several parameters on the recirculation performance. The fully independent analysis of the influence of different properties (carried out with a specifically validated model) is an important innovative result for the application of such ejectors on high temperature fuel cells.
\end{abstract}




\section{Keywords}

Ejector; recirculation; fuel cell; hybrid system.

\section{Introduction}

Ejectors are operative machines able to generate a pressure increase (usually tens of mbars) in a fluid (secondary flow) using the pressure energy of a driving fluid (primary flow) [1] on the basis of the Venturi effect [2]. The primary fluid performs a significant expansion in the primary duct reaching high speed conditions (subsonic, sonic or supersonic flow depending on the duct geometry, the fluid type, pressure and temperature values). The fluids are mixed in the mixing chamber where the high speed of the primary fluid generates the driving force (the Venturi effect [2]) to produce the secondary duct flow. This mixing phase can be considered complete as a proper uniformity is reached in terms of speed, temperature and chemical composition. Then, this highspeed flow enters the diffuser to obtain a partial conversion of the kinetic energy in pressure energy [3]. Therefore, the ejector outlet pressure is higher than the value at the secondary inlet, obtaining a significant compression. The main advantages of these machines (in comparison with blowers [4] operating in the same circuit) are: simplicity, low costs and no moving parts. These aspects generate a significant increase in reliability and durability [5]. However, these devices cannot be controlled in terms of both flow rates and pressures: the outlet properties are just due to the fluid dynamic coupling of the two flows obtained with the ejector geometry (with the duct sections: primary, secondary, mixing chamber and diffuser). So, they are simple, low cost and reliable machines, but not flexible for control and flow rate changes [6]. Due to this control limitation, a detailed modelling activity has to be operated before designing and installing ejectors in a real plant.

Since the previous century, ejectors are used for different applications, such as liquid, alkali or acid transfer, movement of liquids with abrasive particles, and emptying operations of septic tanks. Moreover, in prime mover systems ejectors are used for gas removal (Fig.1 - part A) in the 
condenser of steam power plants [7], and in inverse cycles (refrigeration technology) they are proposed [8-10]. In aircrafts, ejectors can be used for increasing the propelling force, changing the jet direction, increasing auxiliary flow and for aircraft ventilation. In details, for these aircraft applications, experimental tests demonstrated that the ejector performance can be increased with a primary pulsing flow [11].

A further interest on these machines is related to the hybrid plants based on high temperature fuel cells [12-16] (Fig.1 - part B). In details, several researchers proposed these devices for applications in recirculations of high temperature fuel cells. However, due to the high recirculation requirements (especially for carbon deposition prevention in the anodic side) specific improvements based on modelling and experiments are necessary [17-19]. Although these promising results, the application of ejectors in such systems is considered difficult by different works [20,21] due to the mentioned control limitations.

Moreover, it is important to highlight further innovative ejector applications mainly related to the following systems: tanks for energy storage [22], desalinization devices [23], Organic Rankine Cycle (ORC) systems [24], etc.
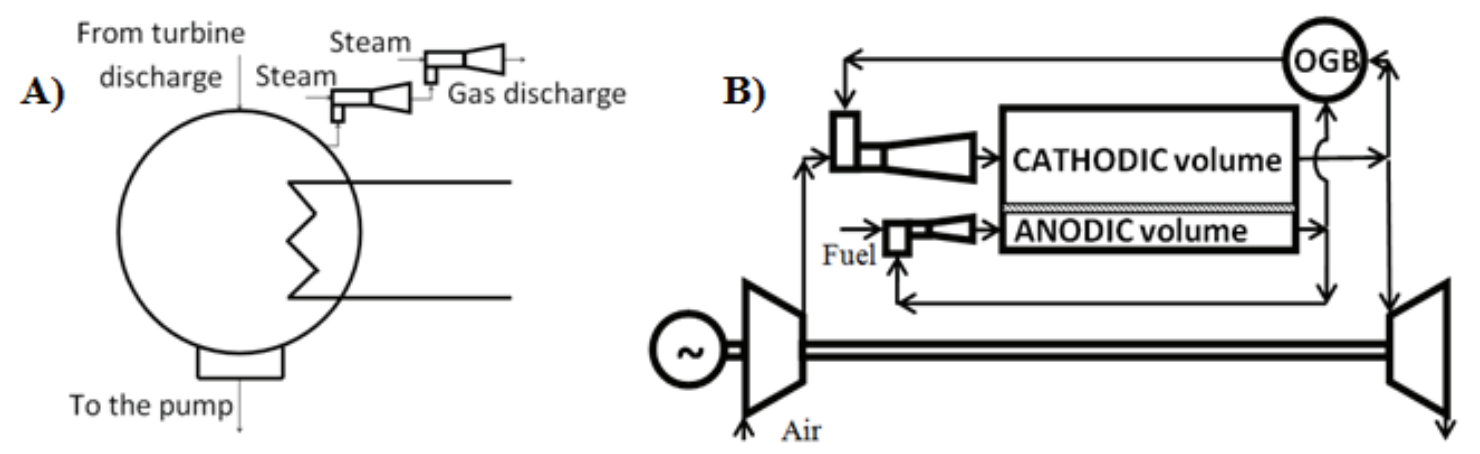

Figure 1. Ejectors in power systems: (A) gas removal in steam power plants, (B) anode and cathode recirculations in SOFC hybrid systems. 
The potential benefits of these machines are motivating research activities especially for hybrid systems. In these cases, ejector operations are affected by important constraints: such as fuel cell inlet temperature, thermal gradients, heat for the reformer, flow composition in the ducts. However, the most significant constraint that requires to completely re-design these ejectors is the limitation in the Steam-To-Carbon Ratio (STCR) in the anodic duct to avoid carbon deposition. To ensure the minimum amount of STCR at both design and part-load operations [25], detailed modelling and calculations are necessary for these components.

In this paper a detailed CFD model is presented and validated for hybrid system applications. Due to a large amount of calculations necessary for this machine (off-design and control issues), the tool was based on modelling solutions to obtain an acceptable compromise between accuracy (performance validated against experimental data) and calculation time. Attention is focused on the geometry necessary for the anodic loop, due to the advanced performance necessary for this device. The main innovative aspects of this work are related to the model validation (based on the experiments performed with a test rig able to emulate an anodic recirculation system) and the extensive analysis on the effects of important parameters related to an anodic loop.

\section{Ejector model}

The ejector model was developed using Fluent considering a 3D Computational Fluid Dynamic (CFD) approach. The model was implemented considering the following governing equations: mass, momentum (three equations due to the 3D approach), energy and the real gas state equation. Since they are standard equations, they are not further discussed here (more details are available in the following book [26]). The numerical solver was the Fluent implicit scheme. Moreover, the spatial discretization was developed considering the "Green-Gauss Cell Based" approach for the gradient and the "Third-Order MUSCL" for the flow and the turbulent kinetic 
energy and dissipation rate. The machine was modelled on the basis of the geometry and the domain show in Tab.1 and Fig.2 respectively.

Table 1. Main details of the ejector geometry considered for this model [17].

\begin{tabular}{|l|c|c|}
\hline Nozzle obstruction section & $\mathrm{A}_{\text {th }} / \mathrm{A}_{1}$ & 2.5 \\
\hline Mixing duct section & $\mathrm{A}_{2} / \mathrm{A}_{1}=\mathrm{A}_{3} / \mathrm{A}_{1}$ & 64.2 \\
\hline Outlet section of the diffuser & $\mathrm{A}_{4} / \mathrm{A}_{1}$ & 985.2 \\
\hline Mixing duct length & $\mathrm{L}_{\text {mix }} / \mathrm{L}_{\text {prim }}$ & 0.49 \\
\hline Length of the diffuser & $\mathrm{L}_{\text {diff }} / \mathrm{L}_{\text {prim }}$ & 1.64 \\
\hline
\end{tabular}

The calculation mesh was obtained with the devoted tool of Fluent considering the following aspects: about 530,000 cells, tetrahedral type, unstructured approach, curvature and proximity (5 cells minimum number) method, 10 inflation levels on the solid boundaries (preliminary calculations showed no significant solution variation increasing the inflation levels, in agreement with the wall treatment performance shown in [27] for the fine mesh). A preliminary mesh was obtained with the Fluent mesher tool. Then, after a preliminary solution, the mesh was improved with the Fluent adapter tool to have a good density increase where necessary. The obtained mesh quality was about 0.5 . This mesh was selected after some preliminary calculations to obtain a good solution independence from the grid [27,28]. Theses preliminary simulations showed about $13 \%$ change in the recirculation ratio (in comparison with the chosen approach) for a mesh composed of 252,000 cells and no significant variations for values higher than 500,000 cells.

The following boundary conditions were considered:

- wall condition for the lateral eternal ejector surface and for the primary duct nozzle (included in the secondary flow as shown in Fig.2);

- inlet condition for both primary and secondary ducts (total pressure, total temperature and fluid composition as input values);

- outlet condition for the diffuser outlet section (static pressure). 


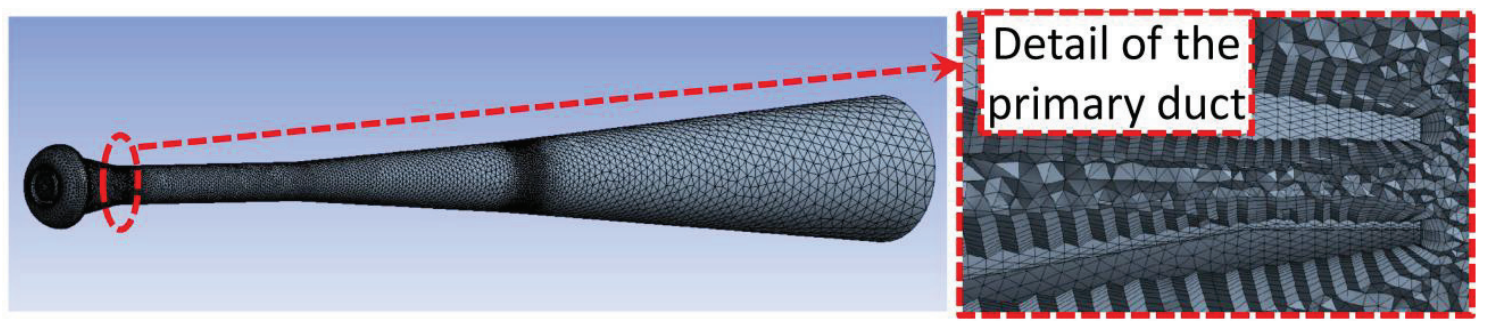

Figure 2. Mesh of the ejector and related details.

The Navier-Stokes equations were used by Fluent implementing the following aspects: compressible and real fluids. Moreover, the k-epsilon turbulence model was included considering the enhanced wall approach and the following options: pressure and thermal gradients, full Buoyancy, curvature correction, compressibility, production limiter. The turbulence model was chosen considering previous CFD calculations on ejectors: in [6] the authors demonstrated (on the basis of a comparison with the Large the Eddy Simulation tool and on results shown in [11]) that the k-epsilon model is an acceptable compromise between the solution accuracy and the calculation time (in agreement with the objectives of this study). For the inlet boundary conditions of the turbulence model, the Fluent default values were used (5\% turbulent intensity, 10 turbulent viscosity ratio) $[27,28]$. According with a preliminary analysis, these values had a negligible effect on the results. The model does not include any specific coefficient for the pressure losses which are calculated with the mentioned CFD approach (with the related k-epsilon turbulence model). Moreover, the model includes the complete heat transfer calculation between the secondary and primary ducts. Since the external thermal losses are low (the ejector is usually installed in an environment close to its operative temperature or well insulated), they are calculated on the basis of a constant heat transfer coefficient to avoid the complete CFD modelization of the external environment. The effectiveness of this simplified approach is shown by the good matching with the experimental data (high temperature tests) in the section devoted to the model validation.

Figure 3 shows a detail (the fluid speed) of a preliminary calculation carried out with the boundary conditions reported in Tab.2. The pressure rise divided by the reference value (not 
reported for confidentiality reasons) was 0.51 . The residuals related to this calculation (and the further simulations shown in the paper) were lower than $10^{-3}$ for continuity, speed and energy and lower than $10^{-4}$ for the turbulence (k-epsilon model). The local aspects shown by Fig.3 are: (i) the speed increase in the primary duct up to sonic conditions (for the pressure values considered in this test), (ii) the Venturi effect in the secondary duct (the central high speed flow drags the secondary flow shown by the slight speed increase at the outlet of the secondary duct), and (iii) the reaching of a good flow uniformity (for the speed in Fig.3) in the mixing chamber (design verification for this duct). Moreover, the CFD tool was also able to verify the good design of the diffuser (especially for the angle) due to no boundary layer separation.

Table 2. Boundary conditions at the duct inlet for a preliminary calculation.

\begin{tabular}{|l|l|c|}
\hline \multirow{3}{*}{ Primary duct } & Fluid & Air \\
\cline { 2 - 3 } & Total pressure & $2.00 \mathrm{bar}$ \\
\cline { 2 - 3 } & Total temperature & $296 \mathrm{~K}$ \\
\hline \multirow{3}{*}{ Secondary duct } & Fluid & Air \\
\cline { 2 - 3 } & Total pressure & $1.02 \mathrm{bar}$ \\
\cline { 2 - 3 } & Total temperature & $296 \mathrm{~K}$ \\
\hline
\end{tabular}

From the global point of view and the related property effects (e.g. inlet pressures, temperatures and flow compositions), several aspects can be analysed considering the nozzle mass flow rate equation $[29,30]$. All the details on the specific property variation is discussed in the text (in correspondence of the related calculation). 


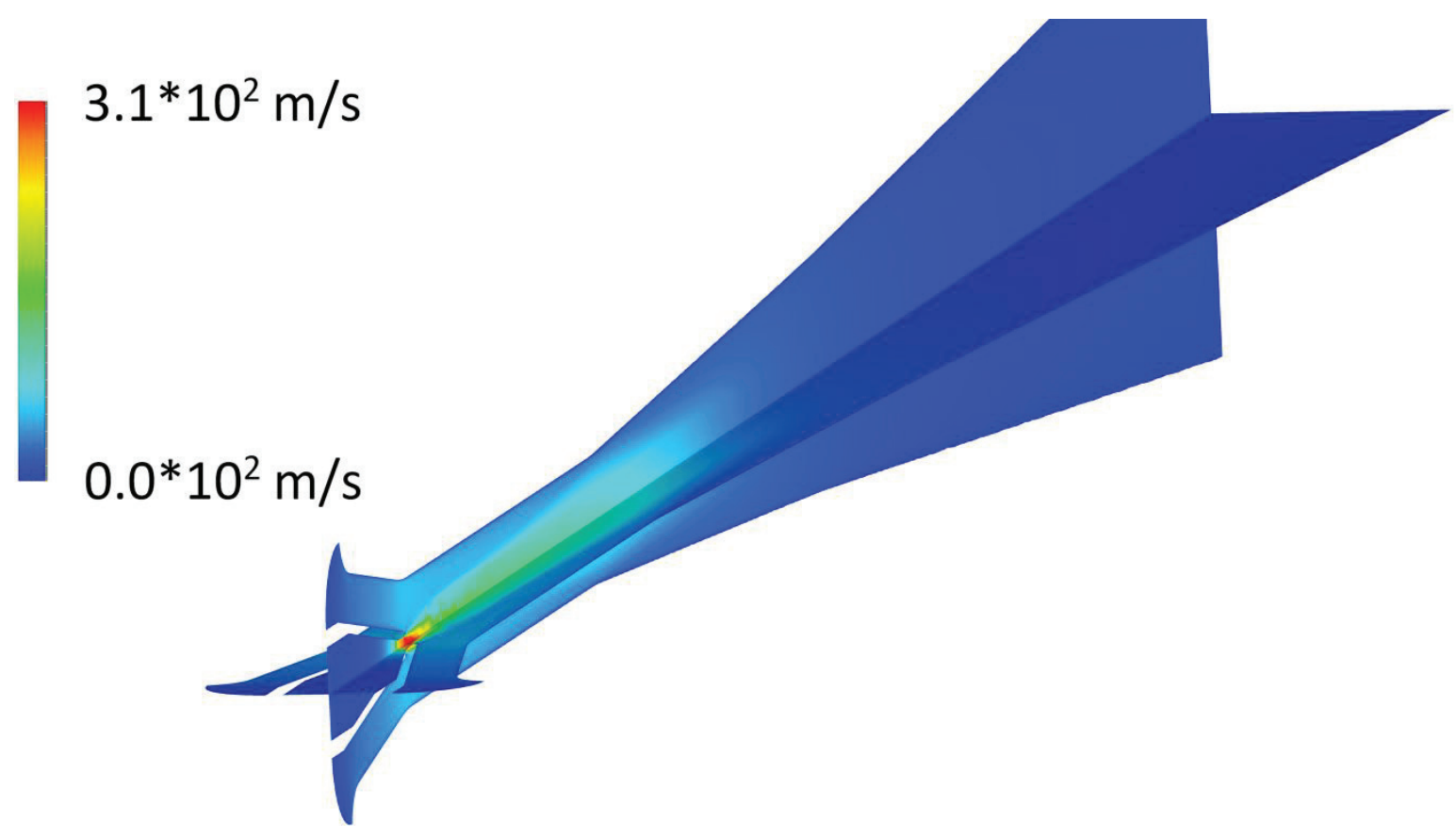

Figure 3. Preliminary calculation: fluid speed on transversal and vertical planes.

\section{Experimental rig}

An experimental facility (Fig.4, part A and B) for tests in anodic recirculations was developed and installed at the University of Genoa by the Thermochemical Power Group. This rig was designed considering a reduced-scale system with a pressure vessel instead of the real fuel cell $[6,15]$. It includes a single stage ejector usually fed by air or different gases in the primary line and connected with a pressure vessel (100 1) to emulate the SOFC anodic volume. A manual valve is installed between the ejector outlet and the vessel inlet for pressure loss change. Moreover, the volume outlet pipe is related to the recirculated flow (connected to the ejector secondary inlet duct). As in a real SOFC anodic loop, the vessel is equipped with a second outlet line managed by a manual valve. This device is able to pressurize the system (up to 5 bar). To perform tests at high temperature conditions (up to $573 \mathrm{~K}$ at the secondary inlet duct), an electrical heater was installed inside the 1001 vessel. Do to operative conditions that are not able to reach the anodic side typical ranges, experimental activities were also performed in similitude conditions, as shown in $[6,15]$. 
Moreover, the test rig includes instrumentation to measure the values of mass flow rate, pressure and temperature in the main circuit sections (Fig.4, part A) $[6,15]$. The mass flow rate in the primary line is measured with standard probes based on the thermal principle without specific problems. On the other hand, the measurement of the ejector outlet flow is carried out with a venturi-based system installed in a 2" pipe. To have reliable results (linked with flow uniformity) it was necessary to install a straight pipe upstream of the device and to couple the probe with a temperature measurement device (since pressure losses can be considered negligible in this pipe, the upstream probes are enough for obtaining the pressure value necessary for the mass flow rate measurement at the ejector outlet).

Moreover, Figure 4 shows (on the right side: parts $\mathrm{C}$ and $\mathrm{D}$ ) the hybrid system emulator rig including an anodic recirculation based on a single stage ejector. While this emulator rig was developed on the basis of the experimental results obtained with the plant show in Fig.4 (part B), the main details and results related to the complete hybrid system emulator are shown in $[31,32]$.

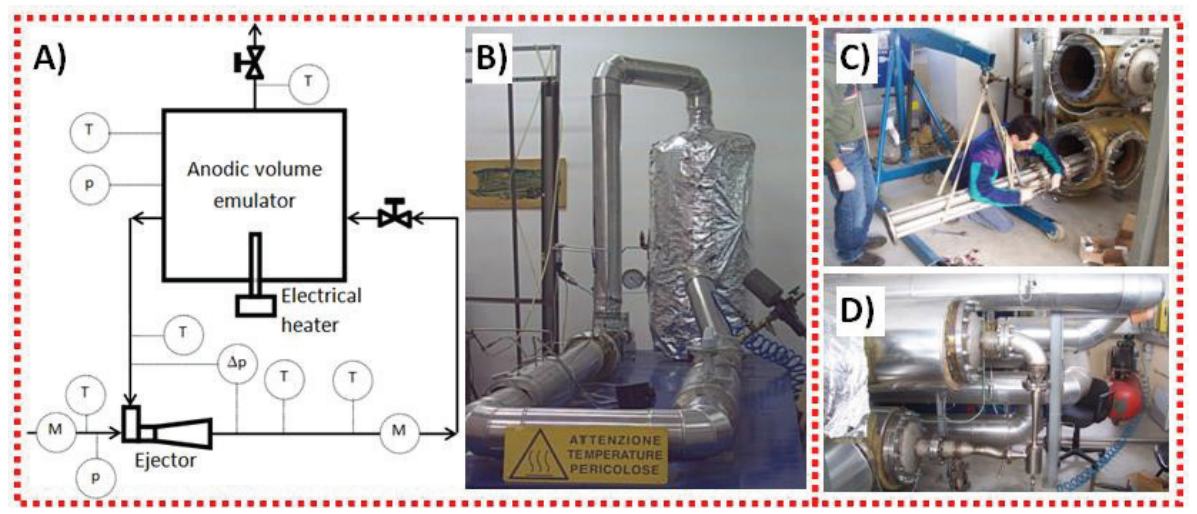

Figure 4. Experimental facility for ejectors ((A) plant layout, (B) facility picture) and the hybrid system test rig ((C) building operations, (D) anodic recirculation). 


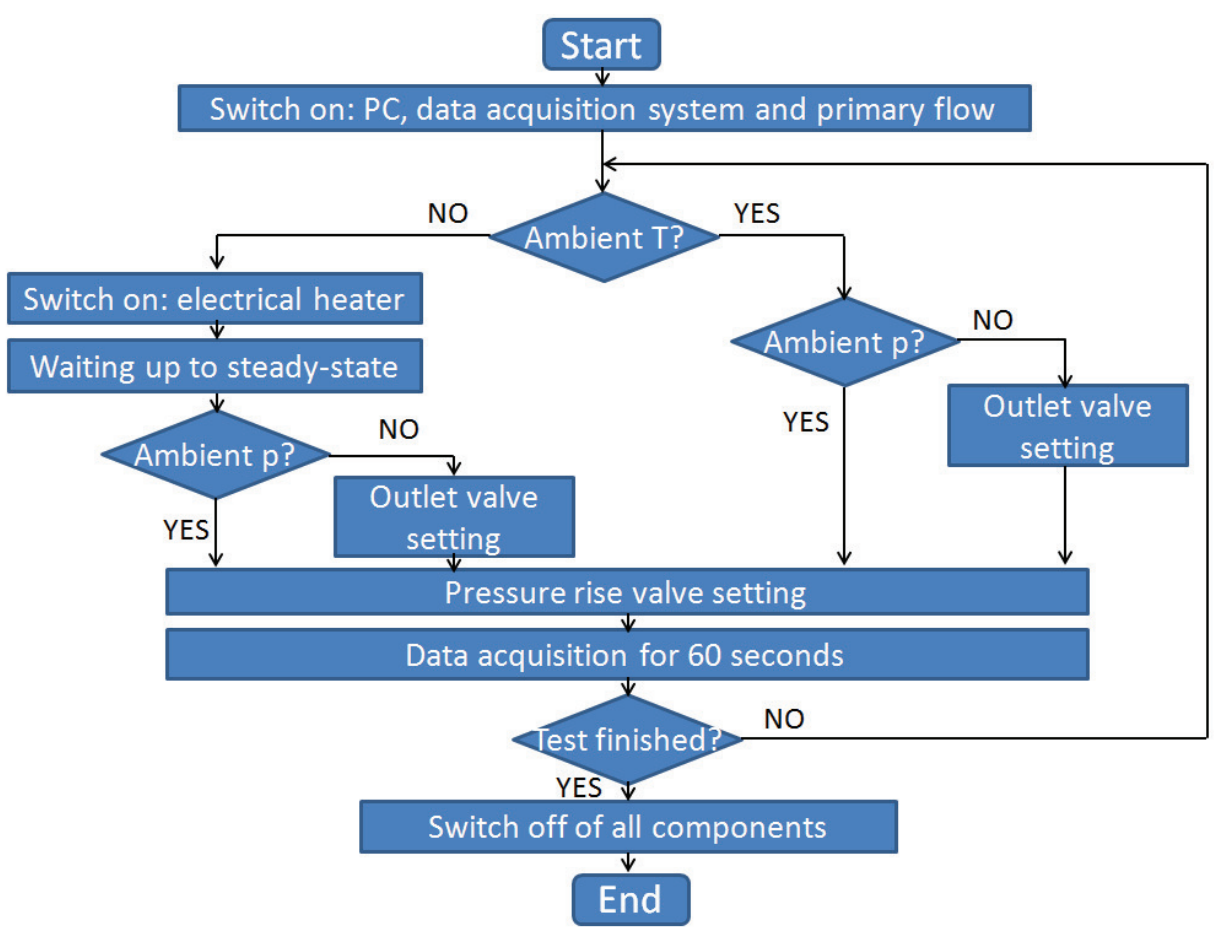

Figure 5. Flowchart related to the test procedure.

To complete the presentation of the ejector rig, Fig.5 shows the flowchart for the experimental operations related to this work. The initial phase is necessary to switch on the data acquisition system, the related PC with the LabVIEW software and the primary flow (opening the apt manual valve connected to the compressed air line). In case of ambient temperature tests, the procedure is quite simple: the outlet manual valve has to be set for pressurized operations, while for atmospheric tests this operation is not necessary. For high temperature tests, it is necessary to switch on the electrical heater and to wait for steady-state thermal conditions for a couple of hours. Moreover, also in this case, the outlet valve has to be managed for pressurized tests. After these preliminary operations, the ejector pressure rise has to be set with the apt manual valve. Then, the actual test with the related acquisition (60 seconds) is performed in steady-state mode or after a property step change (in case of a transient test). Finally, the entire procedure can be repeated (for a further test in different conditions) or diverted to the switch off of all components. 


\section{Experimental validation}

The model was validated considering experimental data obtained with the test rig with recirculation ratio $\left(\mathrm{F}=\mathrm{M}_{2} / \mathrm{M}_{1}\right)$ ranges typical of the anodic side of $\mathrm{SOFC}$ systems (more details about the tested ejector are reported in [17]). The common data for the boundary conditions related to the tests with ambient pressure (in the secondary duct inlet vane) are shown in Tab.3, while the specific values are reported in Fig.6.

Table 3. Boundary conditions (common data) at the duct inlet for the experimental validation of

Fig.6.

\begin{tabular}{|l|l|c|}
\hline \multirow{3}{*}{ Primary duct } & Fluid & Air \\
\cline { 2 - 3 } & Total pressure & $2.00 \mathrm{bar}$ \\
\cline { 2 - 3 } & Total temperature & $296 \mathrm{~K}$ \\
\hline \multirow{2}{*}{ Secondary duct } & Fluid & Air \\
\cline { 2 - 3 } & Total pressure & $1.02 \mathrm{bar}$ \\
\hline
\end{tabular}

Figure 6 shows the ejector characteristic curves obtained at ambient pressure at the inlet of the secondary duct: the pressure rise versus the recirculation ratio is divided by the related reference values, not reported here for confidentiality reasons (as in [17]). While a curve is obtained at ambient temperature at the inlet of the secondary duct $(296 \mathrm{~K})$, the dotted line refers to high temperature tests (operated at $423 \mathrm{~K}$ ). In both cases, the recirculation ratio shows a significant decay increasing the ejector pressure rise (property linked with the fuel cell pressure drop in the anodic side of SOFC systems). Moreover, Fig.6 shows a significant recirculation ratio decay increasing the temperature (the $423 \mathrm{~K}$ case compared with the $296 \mathrm{~K}$ curve). This effect is mainly due to global flow property trend (the temperature increase in the secondary duct inlet vane) instead of local effects. The only aspect to be highlighted with detailed local calculations is the primary flow decay (about 4\%) due to the slight heat transfer from the high temperature secondary duct. This mentioned decrease in the F values is due to the mass flow rate decrease in the secondary duct produced by the temperature increase (it is a typical nozzle behavior $[29,30]$ ). The effect of 
pressurization (pressure increase at the inlet of the secondary duct) is shown in Fig.7 (the pressure in the inlet vane of the primary duct was the double of the related secondary value). Since the primary outlet flow is in sonic condition (as in Fig.3), no additional local phenomena have to be highlighted. However, the effect of the global property change (the pressure variation in the inlet vanes) is significant. Although the recirculation ratio is not significant changing with pressure increase, both primary and secondary mass flow rates have a significant increase due to the increase of the inlet pressure values. This effect is shown in Fig. 7 by the pressure rise increase that is equal to the circuit pressure loss.

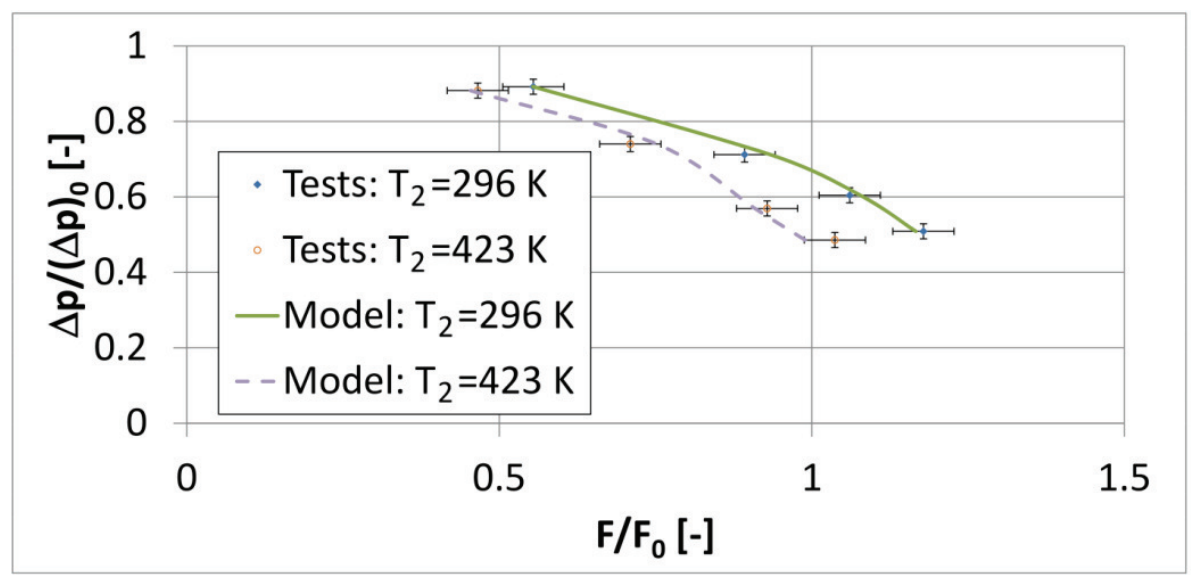

Figure 6. Model validation: ambient pressure at the inlet of the secondary duct.

Both plots (Figs.6 and 7), show the comparison between the calculated values with the model and the related measured data in the rig for the main ejector performance parameter (the recirculation ratio). The calculated curves match with good accuracy the experimental data, especially taking into account the related measurement errors. For all the considered conditions, the calculated data are inside the band corresponding to the measurement maximum errors. As shown in [17], the instrumentation uncertainty is: $\pm 0.25 \%$ for the pressure absolute probes, $\pm 2.5 \mathrm{~K}$ for the temperature measurements, $\pm 2 \%$ for the ejector pressure rise, $\pm 1.5 \%$ for the mass flow rate in the primary duct and $\pm 3 \%$ for the ejector outlet mass flow rate. Since $F$ is the ratio between the 
secondary (calculated subtracting the primary duct flow value from the ejector discharge amount) and the primary mass flow rates, an uncertainty value of $4.9 \%$ was calculated for this parameter.

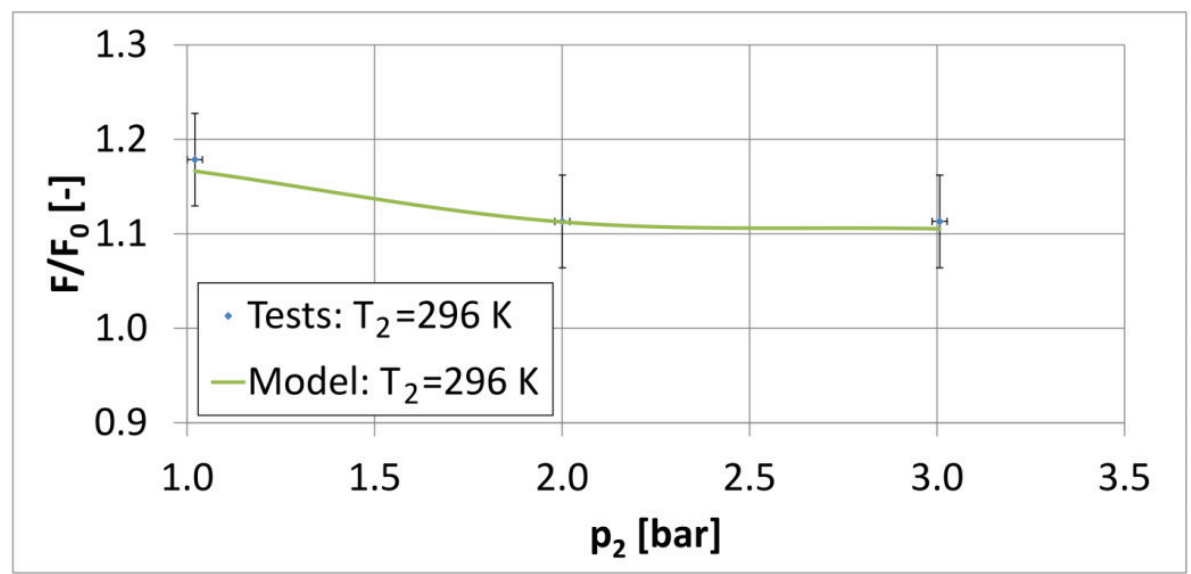

Figure 7. Model validation: pressurization effect $\left(p_{1}=2 \cdot p_{2}\right)$.

Table 4. Operative conditions considered for these calculations (the pressure rise is not reported for confidentiality reasons).

\begin{tabular}{|l|c|c|}
\hline \multicolumn{3}{|c|}{ Primary duct } \\
\hline Total pressure & 15.76 & bar \\
\hline Total temperature & 673 & $\mathrm{~K}$ \\
\hline Composition (mass fractions) & $100 \%$ & $\mathrm{CH}_{4}$ \\
\hline \multicolumn{2}{|c|}{ Secondary duct } \\
\hline Total pressure & 3.72 & $\mathrm{bar}$ \\
\hline Total temperature & 1246 & $\mathrm{~K}$ \\
\hline \multirow{4}{*}{ Composition (mass fractions) } & $43.96 \%$ & $\mathrm{H}_{2} \mathrm{O}$ \\
\cline { 2 - 3 } & $51.46 \%$ & $\mathrm{CO}_{2}$ \\
\cline { 2 - 3 } & $4.19 \%$ & $\mathrm{CO}$ \\
\cline { 2 - 3 } & $0.39 \%$ & $\mathrm{H}_{2}$ \\
\hline
\end{tabular}

\section{Results}

This section shows the results obtained with the validated ejector model. The ejector geometry considered for these results is the same used for the validation (Tab.1). This tool was used to calculate the performance of this ejector under typical conditions of an anodic recirculation of an SOFC system. For this reason, the design operative conditions reported in Tab.4 (shown in [12] for 
the composition and in [33] for the temperatures) were taken into account. A pressure rise different from $[12,33]$ was considered to have a recirculation ratio typical of such SOFC systems (the ejector geometry is different from $[12,33])$. Special attention was devoted to the Steam-to-Carbon ratio (defined in Eq.1) due to its importance to avoid carbon deposition in the SOFC anodic circuit [25].

$$
S T C R=\frac{\mathrm{n}\left(\mathrm{H}_{2} \mathrm{O}\right)}{\mathrm{n}\left(\mathrm{CH}_{4}\right)+\mathrm{n}(\mathrm{CO})}
$$

A sensitivity analysis was carried out on the ejector secondary inlet temperature $\left(\mathrm{T}_{2}\right)$ and pressure $\left(\mathrm{p}_{2}\right)$, considering variations related to off-design operations of SOFC systems [25] (the importance of the property variation at the inlet of secondary duct is also shown in [34]). Moreover, also the effect of pressure rise increase (as generated by SOFC degradation) was taken into account. The plots (Figs.8-10) related to the variation of these properties were referred to the design values of the recirculation ratio $\left(\mathrm{F}_{\mathrm{D}}\right)$, the Steam-to-Carbon ratio $\left(\mathrm{STCR}_{\mathrm{D}}\right)$ and the pressure rise $(\Delta \mathrm{p})_{\mathrm{D}}$. Although $\mathrm{F}_{\mathrm{D}}, \mathrm{STCR}_{\mathrm{D}}$ and $(\Delta \mathrm{p})_{\mathrm{D}}$ are not reported for confidentiality reasons, Figs.8-10 shows the influence of the variation of each mentioned property on the recirculation and Steam-to-Carbon ratios. Due to a primary duct in choked conditions for all the calculations, no significant impact of local phenomena has to be mentioned here on the sensitivity analysis (also the influence of the heat transfer variation is almost negligible for the property change considered here). The almost linear trend shown in Figs.8-10 is not in disagreement with the data shown in Figs.6-7 because in this section the property range variation is small for $T_{2}$ and $p_{2}$. Moreover, also the sensitivity results related to the ejector pressure rise shows an almost linear trend due to operative conditions in a zone close to this linearity (as reducing the characteristic curve in the Fig.6 to a small zone). So, although the ejector behavior is not linear, considering such operation ranges typical of system off-design or degradation a linear trend generates $0.2 \%$ maximum errors in comparison with the calculated data by the model. However, more significant property variations cannot be treated with linear trends (as visible in Figs.6-7). Since the inlet composition is constant for both ducts (shown in Tab.4) the 
STCR is only dependent on the mass flow rate (and, as a consequence, on the recirculation factor) trends.

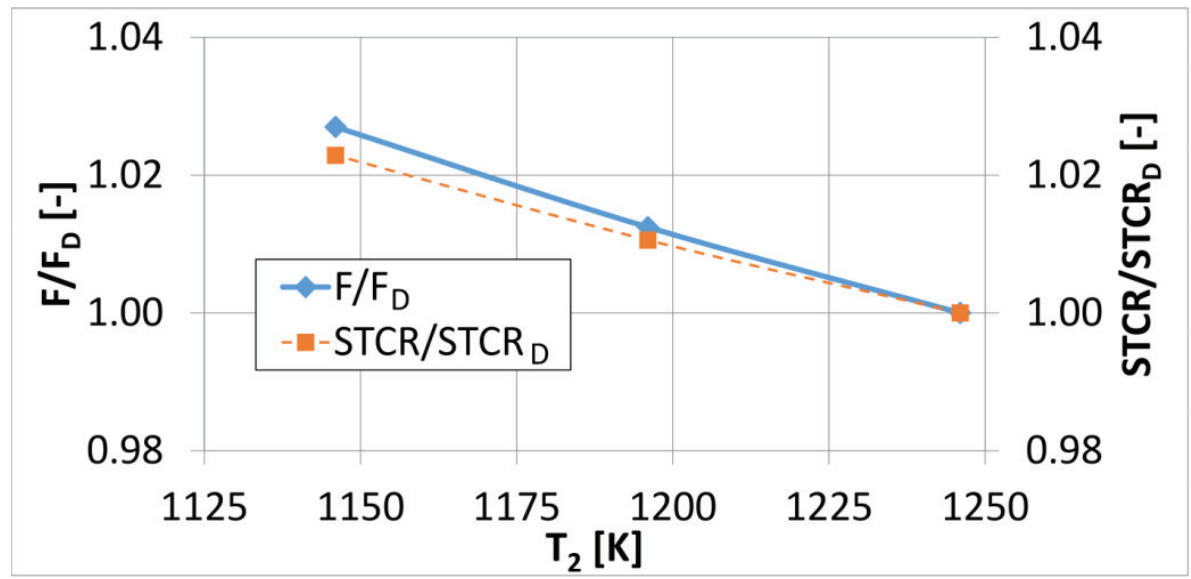

Figure 8. Sensitivity analysis: effect of the inlet temperature of the secondary duct.

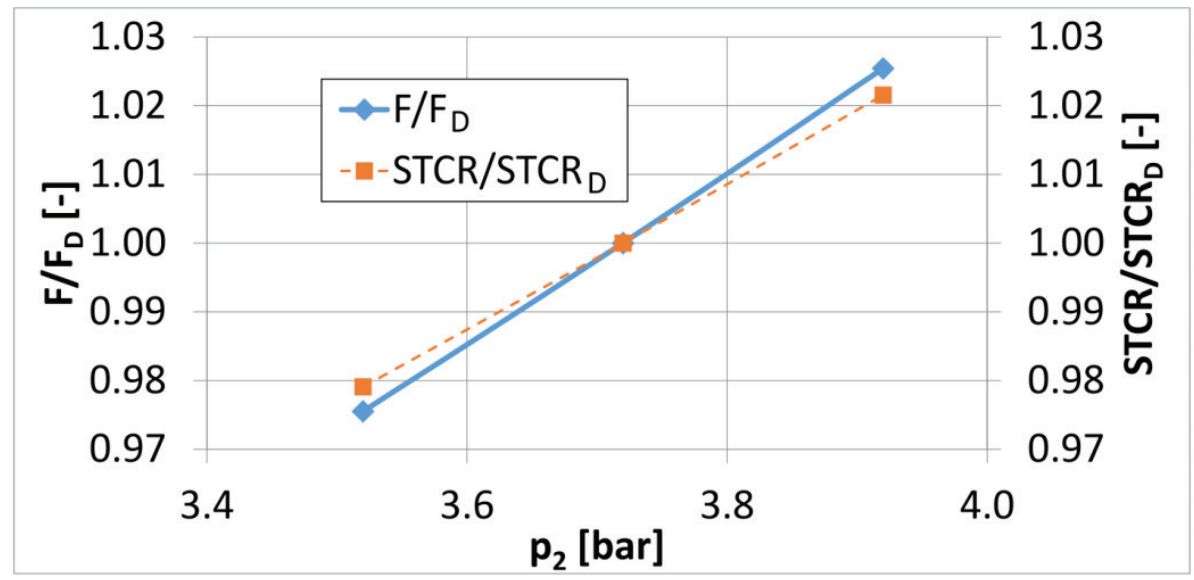

Figure 9. Sensitivity analysis: effect of the inlet pressure of the secondary duct.

The variation of the recirculation ratio shown in Figs.8-9 is due to the behavior of the secondary duct (in agreement with the typical nozzle behavior $[29,30])$ ). So, while the temperature increase generated a recirculation ratio decrease (Fig.8), the pressure increase (Fig.9) has a positive effect on the ejector performance. Finally, Fig.10 shows the recirculation ratio decay produced by the ejector pressure rise increase, as in agreement with Fig.6 and [17]. 


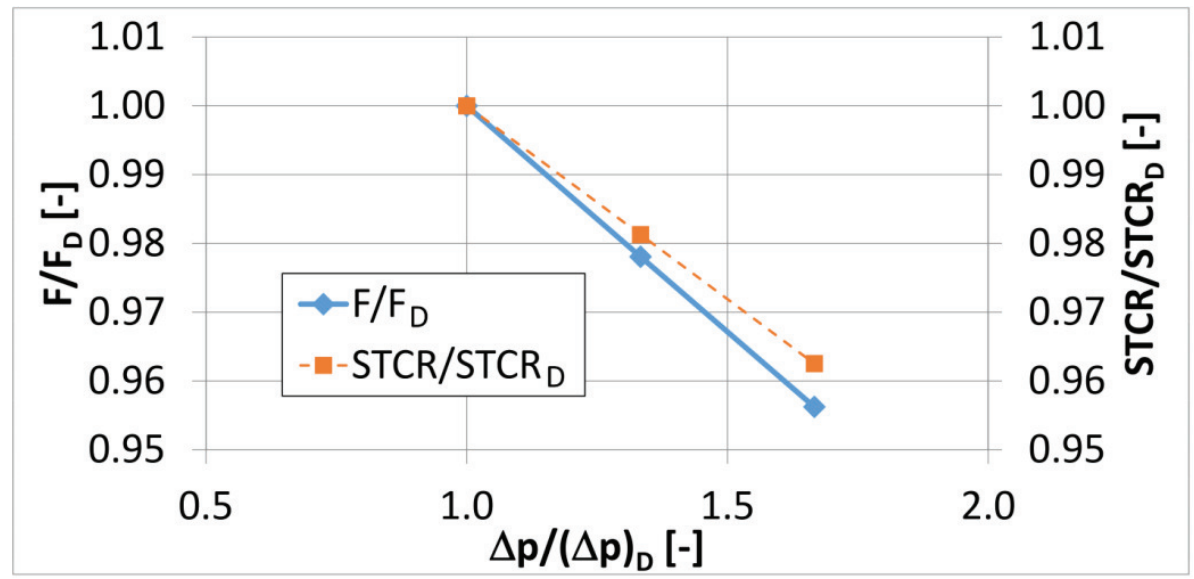

Figure 10. Sensitivity analysis: effect of the ejector pressure rise.

\section{Conclusions}

The results presented in this paper were obtained with a 3D CFD model developed in Fluent at the University of Genoa. This is an important activity especially for fuel cell applications. In details, especially the SOFC anodic recirculation requires a high performance ejector operating at conditions significantly different from standard applications of these machines. So, detailed calculation tools are essential for the component design and off-design analysis. The main results presented in this paper are shown in the following points.

- The 3D CFD ejector model was successfully validated against experimental data obtained with an anodic recirculation test rig available at the University of Genoa. The calculated values match with good accuracy the experimental data considering different operative conditions: they are inside the band corresponding to the measurement maximum errors.

- The validated model was used to perform design and off-design analysis on an ejector for SOFC anodic recirculations. While the design operative conditions were based on the data shown in [33], a sensitivity analysis was carried out considering 
typical variation of parameters in SOFC systems (off-design behavior or SOFC degradation).

- The sensitivity analysis (maximum variations: $100 \mathrm{~K}$ for $\mathrm{T}_{2}, 0.2$ bar for $\mathrm{p}_{2}$ and $60 \%$ for $\left.\Delta \mathrm{p} /(\Delta \mathrm{p})_{\mathrm{D}}\right)$ shows that a linear trend generates $0.2 \%$ maximum errors in comparison with the calculated data by the model.

This validated tool will be used at the University of Genoa for detailed analysis of different SOFC anodic loops. In details, special attention will be devoted on the application of different alternative fuels [35], such as biogas, including SOFC degradation impact [36].

\section{Acknowledgements}

The test rig was partially funded by (i) FP6 and FP7 EU projects, (ii) National projects, and (iii) Rolls-Royce Fuel Cell Systems.

\section{Nomenclature}

$\underline{\text { Variables }}$

$\begin{array}{ll}\text { A } & \text { section }\left[\mathrm{m}^{2}\right] \\ \text { F } & \text { recirculation ratio [-] } \\ \text { L } & \text { length }[\mathrm{m}] \\ \mathrm{M} & \text { mass flow rate }[\mathrm{kg} / \mathrm{s}] \\ \mathrm{n} & \text { number of moles }[\mathrm{mol}] \\ \mathrm{p} & \text { pressure }[\mathrm{Pa}] \\ \text { STCR } & \text { Steam-To-Carbon Ratio [-] } \\ \text { T } & \text { temperature }[\mathrm{K}]\end{array}$

$\underline{\text { Subscripts }}$ 


$\begin{array}{ll}0 & \text { reference } \\ 1 & \text { primary duct inlet } \\ 2 & \text { secondary duct inlet } \\ 3 & \text { diffuser inlet } \\ 4 & \text { diffuser outlet } \\ \text { D } & \text { Design } \\ \text { diff } & \text { diffuser } \\ \text { mix } & \text { mixing } \\ \text { prim } & \text { primary } \\ \text { th } & \text { thickness }\end{array}$

\section{Acronyms}

$\begin{array}{ll}\text { CFD } & \text { Computational Fluid Dynamic } \\ \text { MUSCL } & \text { Monotonic Upwind Scheme for Conservation Laws } \\ \text { OGB } & \text { Off-Gas Burner } \\ \text { ORC } & \text { Organic Rankine Cycle } \\ \text { PC } & \text { Personal Computer } \\ \text { SOFC } & \text { Solid Oxide Fuel Cell }\end{array}$

\section{References}

[1] Huang B.J., Chang J.M., Wang C.P., Petrenko V.A., A 1-D analysis of ejector performance. International Journal of Refrigeration, 22 (1999) 354-364.

[2] Wang J., Dai Y., Zhang, T., Ma, S., Parametric analysis for a new combined power and ejector-absorption refrigeration cycle. Energy, 34 (2009) 1587-1593.

[3] Desevaux P., A method for visualizing the mixing zone between two co-axial flows in an ejector, Optic and Laser Engineering. 35 (2001) 317-323. 
[4] Milewski J., Miller A., Mozer E., Fwiercz T., High Temperature Micro-Fan for Solid Oxide Fuel Cell Applications. Fuel Cells, 15 (2015) 580-587.

[5] Aronson K.E., Ryabchikov A.Y., Kuptsov V.K., Murmanskii I.B., Brodov Yu.M., Zhelonkin N.V., Khaet S.I., Ejectors of power plants turbine units efficiency and reliability increasing. Journal of Physics: Conference Series, 891 (2017) 1-7.

[6] Ferrari M.L., Bernardi D., Massardo A.F., Design and testing of ejectors for high temperature fuel cell hybrid systems. Journal of Fuel Cells, Science and Technology, 3 (2006) 284-291.

[7] Acton O., Caputo C., Generation plants. UTET (in Italian).

[8] Sun D.-W., Variable geometry ejectors and their applications in ejector refrigeration systems. Energy, 21 (1996) 919-929.

[9] Rashidi M.M., Aghagoli A., Raoofi R., Thermodynamic analysis of the ejector refrigeration cycle using the artificial neural network. Energy 129 (2017) 201-215.

[10] Croquer S., Poncet S., Aidoun Z., Turbulence modeling of a single-phase R134a supersonic ejector. Part 1: Numerical benchmark. International Journal of Refrigeration, 61 (2016) 140152.

[11] Vermeulen P.J., Ramesh V., Miller D.N., Yagle P.J., Bender E.E., Ejector pumping enhancement through pulsing primary flow, ASME Turbo Expo 2002, Amsterdam, The Netherlands.

[12] Marsano F., Magistri L., Massardo A.F., Ejector performance influence on a solid oxide fuel cell anodic recirculation system. Journal of Power Sources, 129 (204) 216-228.

[13] Chen J., Li J., Zhou D., Zhang H., Weng S., Control strategy design for a SOFC-GT hybrid system equipped with anode and cathode recirculation ejectors. Applied Thermal Engineering, 132 (2018) 67-79.

[14] Volkova Y.V., Ershov M.I., Munts V.A., Fluid dynamics parameters of a high temperature ejector for SOFC anode gas recirculation. Journal of Physics: Conference Series, 891 (2017) 012187_1-6. 
[15] Ferrari M.L., Traverso A., Massardo A.F, Smart polygeneration grids: Experimental performance curves of different prime movers. Applied Energy, 162 (2016) 622-630.

[16] Kandepu R., Imsland L., Foss B.A., Stiller C., Thorud B., Bolland O., Modeling and control of a SOFC-GT-based autonomous power system. Energy 32 (2007) 406-417.

[17] Ferrari M.L., Pascenti M., Massardo A.F., Ejector Model for High Temperature Fuel Cell Hybrid Systems: Experimental Validation at Steady-State and Dynamic Conditions. Journal of Fuel Cell Science and Technology, 5 (2008) 041005_1-7.

[18] Ferrari M.L., Pascenti M., Magistri L., Massardo A.F., Hybrid System Test Rig: Start-up and Shutdown Physical Emulation. Journal of Fuel Cell Science and Technology, 7 (2010) 021005_1-7.

[19] Ghigliazza F., Traverso A., Massardo A.F., Wingate J., Ferrari M.L., Generic Real-Time Modeling of Solid Oxide Fuel Cell Hybrid Systems. Journal of Fuel Cell Science and Technology, Vol. 6 (2009) 021312_1-7.

[20] Jia Z., Sun J., Dobbs H., King J., Feasibility study of solid oxide fuel cell engines integrated with sprinter gas turbines: Modeling, design and control. Journal of Power Sources, 275 (2015) 11-125.

[21] Curletti F., Gandiglio M., Lanzini A., Santarelli M., Maréchal F., Large size biogas-fed Solid Oxide Fuel Cell power plants with carbon dioxide management: Technical and economic optimization. Journal of Power Sources, 294 (2015) 669-690.

[22] Chen L.X., Hu P., Zhao P.P., Xie M.N., Wang D.X., Wang F.X. A novel throttling strategy for adiabatic compressed air energy storage system based on an ejector. Energy Conversion and Management, 158 (2018) 50-59.

[23] Samaké, O., Galanis, N., Sorin, M., Thermo-economic analysis of a multiple-effect desalination system with ejector vapour compression. Energy, 144 (2018) 1037-1051. 
[24] Chen J., Huang Y., Niu Z., Chen Y., Luo X., Performance analysis of a novel organic Rankine cycle with a vapor-liquid ejector. Energy Conversion and Management, 157 (2018) $382-395$.

[25] Ferrari M.L., Advanced control approach for hybrid systems based on solid oxide fuel cells, Applied Energy, 145 (2015) 364-373.

[26] Eckert M., The Dawn of Fluid Dynamics: A Discipline Between Science and Technology. 2006, Wiley.

[27] Besagni G., Mereu R., Chiesa P., Inzoli F., An Integrated lumped parameter-CFD approach for off-design ejector performance evaluation. Energy Conversion and Management, 105 (2015) 697-715.

[28] Bernardi D., Bozzolo M., Marsano F., Tarnowski O., Agnew G., Ejectors Design in the RollsRoyce 1 MW Hybrid System. ASME Paper 2005-GT-68085, ASME Turbo Expo 2005, Reno, Nevada (USA).

[29] Çengel Y.A., Cimbala J.M., Fluid Mechanics: Fundamentals and Applications, Third Edition, McGraw - Hill, 2013.

[30] Dang Le Q., Mereu R., Besagni G., Dossena V., Inzoli F., Computational fluid dynamics modeling of flashing flow in convergent-divergent nozzle. ASME: Journal of Fluids Engineering 140 (2018) 101102-1 - 101102-22. doi:http://dx.doi.org/10.1115/1.4039908

[31] Ferrari M.L., Pascenti M., Magistri L., Massardo A.F., MGT/HTFC Hybrid System Emulator Test Rig: Experimental Investigation on the Anodic Recirculation System. Journal of Fuel Cell Science and Technology, 8 (2011) 021012-1,9.

[32] Ferrari M.L., Massardo A.F., Cathode-anode side interaction in SOFC hybrid systems. Applied Energy, 105 (2013) 369-379.

[33] Ferrari M.L., Traverso A., Massardo A.F., Transient Analysis of Solid Oxide Fuel Cell Hybrids. Part B: Anode Recirculation Model. ASME Turbo Expo 2004, Vienna, Austria. 
[34] Rao S.M.V., Jagadeesh G., Studies on the effects of varying secondary gas properties in a low entrainment ratio supersonic ejector. Applied Thermal Engineering 78 (2015) 289-302.

[35] Garbarino G., Bellotti D., Finocchio E., Magistri L., Busca G., Methanation of carbon dioxide on Ru/A12O3: Catalytic activity and infrared study. Catalysis Today, 277 (2016) 21-28.

[36] Zaccaria V., Tucker D., Traverso A., Operating strategies to minimize degradation in fuel cell gas turbine hybrids. Applied Energy, 192 (2017) 437-445. 